\title{
DEVELOPMENT OF A LUMPED PARAMETER MODEL OF AN AEROSPACE PUMP FOR CONDITION MONITORING PURPOSES
}

\author{
Geneviève Mkadara*, Pr. Jean-Charles Maré \\ Institut Clément Ader, INSA de Toulouse, 3 rue Caroline Aigle, 31400 Toulouse, France \\ * Corresponding author: Tel.: +33 442 858190; E-mail address: mkadara@insa-toulouse.fr
}

\begin{abstract}
This paper presents the development of a helicopter axial piston pump model with condition monitoring in mind. Industrial constraints and needs ask for modelling with a lumped-parameter approach and require model architecture to be addressed with care. The aim of the proposed model is to assess the merits of pump leakage monitoring through measurement of case pressure. Once reviewed the state of the art in pump modelling, the slipper/swashplate interface is taken as an example to propose and implement in Simcenter AMESim a variable gap height model. The simulation results show that commonly used lumped-parameter models overestimate leakage. It also points out that average leakage at slipper may reverse at high pump displacement.
\end{abstract}

Keywords: Axial piston pump, Helicopters, Modelling, Model architecting

\section{MOTIVATION}

In the current years, as an increasing interest has been brought to the industry on costs reduction and client satisfaction, maintenance has been under scrutiny for all the benefits that its improvement can bring. One of the main potential of advances is to transit from scheduled maintenance to predictive maintenance. This change of paradigm significantly increases product availability through a prediction of its remaining functional life-time. Steps to switch from planned to predictive maintenance are condition-based maintenance and condition monitoring. This trend is being considered by the authors' industrial partner, a rotorcraft manufacturer.

\subsection{Industrial needs}

For helicopters (H/C), maintenance of hydraulics is mainly scheduled with resort to the definition of time between overhauls (TBO), in particular for pumps and servoactuators. Flight controls of medium and heavy class $\mathrm{H} / \mathrm{C}$ involve non reversible servoactuators that are hydraulically supplied. Therefore any pump failure is safetycritical and leads to rotorcraft grounding or mission aborting (and unscheduled landing) if failure happens in flight. A previous paper [1] has reported reliability considerations for axial piston pumps that are installed on Airbus Helicopter fleet. Degradation of pump performance can be detected through observation of several measurements, e.g. acceleration [2] or discharge pressure [3]. As pump degradation often leads to increased internal leakage, an attractive solution consists in measuring the case drain flow, as addressed in [4]. In order to investigate the interest of the latter option, the reported work aims at developing an axial pump simulation model that is sufficiently realistic regarding the real internal leakage.

Two main schools of thoughts can be highlighted for general modelling: data-driven against physics-based. Data-driven approaches identify patterns from measured data and do not necessitate any knowledge on the modelled system. On the contrary, physics-based approaches rely on detailed internal system knowledge. When this latter approach is applied to engine-driven, variable-displacement, and pressure-compensated axial piston pumps, two types of models have been developed: distributed-parameter (sometimes called 3-D) models $[5,6]$ and lumped-parameter (sometimes called 1-D) models $[7,8]$.

Not being a hydraulic pumps Original Equipment Manufacturer (OEM), the rotorcraft manufacturer does not have access to extensive pump test data, which leaves out the data-driven 
approach for pump modelling. On the other hand, the authors' industrial partner does not need very detailed 3-D models which generally require high computation loads and a lot of supplier proprietary information. In practice, the company needs a system-level pump model that can be interfaced with other sub-models of the $\mathrm{H} / \mathrm{C}$ hydraulic systems. These reasons have favoured the adoption of a lumped-parameter approach for modelling the pump under study. Leakage being the focus of the monitoring approach, it is mandatory that the 1-D model includes the pump leakage paths. This contribution reports how the internal leakage can be modelled more accurately in the lumped-parameter frame, considering the gaps as varying quantities instead of fixed input parameters, as always assumed in this frame.

\subsection{Industrial constraints}

From the industrial point of view, the monitoring approach shall be sufficiently generic to be applicable to most axial piston hydraulic pumps of the fleet, throughout all $\mathrm{H} / \mathrm{C}$ categories and flight operation types. In this light, the sensors used for monitoring shall not be pump intrusive, in order to not require any alteration of already certified pumps. The number of sensors added to the existing ones has to be minimized for cost and weight considerations. Moreover, the pump case drain flow cannot be measured directly on helicopters due to safety issues. This is why measuring the pressure directly at pump case port is used as an alternative in the present work. In our application the reservoir is opened to atmospheric pressure and there is no equipment prone to clogging on the return line. The hydraulic system at case port can then modelled as a fixed impedance. Finally, the monitoring approach shall be robust against temperature and atmospheric pressure variations induced by the wide operational domain of helicopters (temperatures ranging from $-40^{\circ} \mathrm{C}$ to $+50^{\circ} \mathrm{C}$, and altitude as high as $7000 \mathrm{~m}$ ).

This paper presents the development of a lumped-parameter simulation model of an axial piston pump meeting the above constraints. First, the model architecture is discussed. Then the pump model, its implementation and some simulation results are described with focus on the slipper/swashplate interface model that includes a variable gap height. Shortcomings of the presented model and ways to improve it conclude this publication.

\section{ARCHITECTURE OF PUMP MODEL}

The pump model is developed to meet an industrial need - assess the merits of case drain pressure measurement for monitoring the $\mathrm{H} / \mathrm{C}$ pump through analysis of its internal leakage. As such, the model shall meet the requirements defined in Table 1. These requirements are either linked to the project purpose, or to the long-term durability of the model. The first requirement category is to be answered through modelling, while most of the second category can be managed through a proper model architecture.

Model architecture is of primary interest in an industrial context, where models need to be easily modified and reused by different actors. It consists in representing blocks (or super components, or sub-models) in a structured manner, including how they interconnect at their ports with other blocks or with the full model environment. When possible, explicit distinctions should be made to indicate whether the interconnections are considered as power or signal type. Several colours can also be used to differentiate technological domains. Defining an appropriate architecture is a necessary prerequisite to meet the durability requirement for an industrialized model (a model to be used in an industrial context). Not taking it into account

Table 1: List of requirements for the pump model

\begin{tabular}{ll}
\hline \multicolumn{2}{l}{ Project Purpose } \\
\hline Rq1 & Shall simulate accurate behaviour of internal leakage, as well as suction and discharge pressure and flow \\
Rq2 & Shall be ready for simulation of pump degradation leading to increased internal leakage \\
Rq3 & Shall enable to assess the monitoring approach \\
\hline Durability \\
\hline Rq4 & Shall be as generic as possible for further modifications, easy to assemble and modify (e.g. changing the \\
& number of pistons) \\
Rq5 & Shall allow for parameters and mathematical expression modifications \\
Rq6 & Shall grant easy access to the basic components of the model \\
Rq7 & Shall be usable as a digital twin, also as "plug and simulate" (only applicable to the whole pump model) \\
\hline
\end{tabular}


leads to prototype-like models, with poor readability, capitalization and even potential for re-use of extension for anyone who was not in charge of the first model issue.

Model architecting is seldom discussed in the literature, because it initially stems out of overall shared pragmatism. Data-driven or 3-D models generally do not need to be architected. For lumped-parameter models, architecture is usually managed implicitly thanks to modellers' experience. Several published papers dealing with 1-D modelling of axial piston pumps show structured model, however without any discussion on architecting or structuration methodology, e.g. [8, 9]. Some lumpedparameter software editors now propose applications for automatic generation of pump models, following a pre-defined topologic architecture, e.g. [10]. Maré and Akitani [11] described the modelling of an electro-mechanical actuator and its associated architecture. In their work, the model architecture is derived from the product topology itself. In [12], Maré proposed a set of standard requirements for models, two of these requirements being "Workshare" and "Capitalization". It is there emphasized that an architecture based on the real product topology helps the understanding and reuse of the model, allowing to partially meet both requirements. It is the authors' opinion that model architecture should be defined during the first phases of a project, anticipating future modifications, extension or reuse of the model.

In practice, this task is iterative because it requires the interfaces between the blocks and their environment to be identified exhaustively. Once done, the blocks themselves can be filled with models which level of detail depends on the current engineering task needs. Depending on this level, some interconnections can remain (partially or totally) unused. The example of the pump block on Figure 1 is used to illustrate this last statement. This pump block shows every pump ports and interfaces:

- For hydraulics: Suction (s), Discharge (d), and Case ports (c) with pressure (P) and volume flow rate $(\mathrm{Q})$ at each port;

- For mechanics: Torque $(\Gamma)$ and angular velocity $(\omega)$, at drive shaft $(\mathrm{m})$ and base (b);

- The thermal port with temperature (T) and heat flux $(\Phi)$.

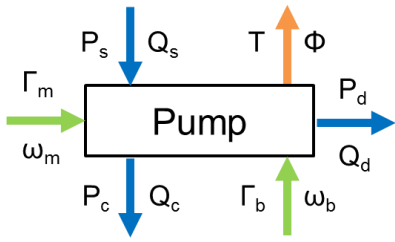

Figure 1: Schematics of pump model ports and interconnections to its environment

If the modeller wants to make a purely hydraulic model, both thermic and base ports will be totally unused. In this use case, the driving port will be partly used, as only the rotating speed is necessary for the modelling of the pumping effect.

Considering the practical implementation of the architecture, the authors present here two architecting approaches for an axial piston pump model The topology of such pump is shown on Figure 2-a, adapted from an EATON document. The first architecting approach, highlighted on Figure 2-b, defines blocks from pump inner functions which come in four: pump fluid, distribute fluid, regulate flow, and collect leakages. On Figure 2-c the model is structured per pump part as a second. Both Figure 2-b and Figure 2-c make the distinction between mechanical and hydraulic interconnection through the use of colours. Thermal interconnections are not shown for the sake of clarity.

Durability requirements of Table 1 are used in order to choose between these two candidate model architectures. Except for Rq7 which is only applicable to the full pump model, the consequences of the durability requirements on architecture are the following:

- Rq4 - At least one block per pump part should be defined, the interconnections with other blocks shall be straightforward and the architecture prepared for future modifications;

- Rq5 - The blocks should be modifiable whiteboxes;

- Rq6 - The architecture should be less than two-blocks deep, i.e. the models shall be available opening two block boxes at most, including the pump block.

These considerations, regarding $\mathrm{Rq} 4$ in particular, speak in favour of the topology-based architecture of Figure 2-c. 
a)

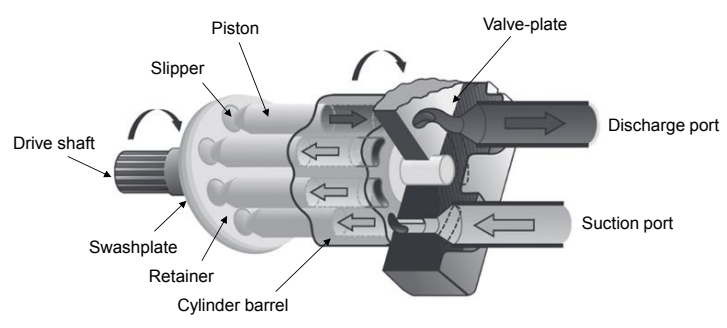

b)



c)



Figure 2: Pump topology and proposed architectures - a) pump cut, b) architecture by function, c) architecture by pump part

\section{PUMP MODEL}

In Table 1, Rq1 requires the simulation of leakage, case drain pressure, as well as pressure and flow at discharge and suction ports. An extensive work has been done to propose analytical models of pump main leakage paths, an interesting entry point being [13]. The synthesis of literature review is given in Table 2, considering both lumped and distributedparameter models. The review focusses on the considered physical effects at leakage interfaces. When the interface is not considered in the paper, cells are coloured in grey. If there is no explicit mention to a given physical effect, the cell is left blank. The last column highlights the contribution of the model described in this communication.

Each listed source meets a particular need, favouring one model type. References [14], [5] and [6] describe in a very detailed way Computational Fluid Dynamics (CFD) models developed to study the influence of the pump design on its performance. Reference [15] discusses the slipper/swashplate interface from a lubrication point of view. Reference [7] aims at deriving lumped-parameter analytical equations of the pump flows. Reference [16] develops a 1$D$ model to study the influence of the hydraulic system on the pump behaviour, while reference
[17] highlights the AMESim software capacities for pump modelling. Table 2 highlights the discrepancy between lumped and distributedparameter modelling approaches. The first type of approaches considers far fewer physical phenomena compared to the second one. Pure lumped-parameter models of axial piston pumps only consider leakage with constant gap heights. On its part, this paper deals with the way to introduce variable gaps in a 1-D modelling paradigm. After having introduced generic lumped-parameter models of leakages, it focusses on the slipper/swashplate interface shown on Figure 3.



Figure 3: Slipper interface schematics adapted from [18] 
Table 2: Synthesis of main contributions relative to leakage modelling of axial piston pumps

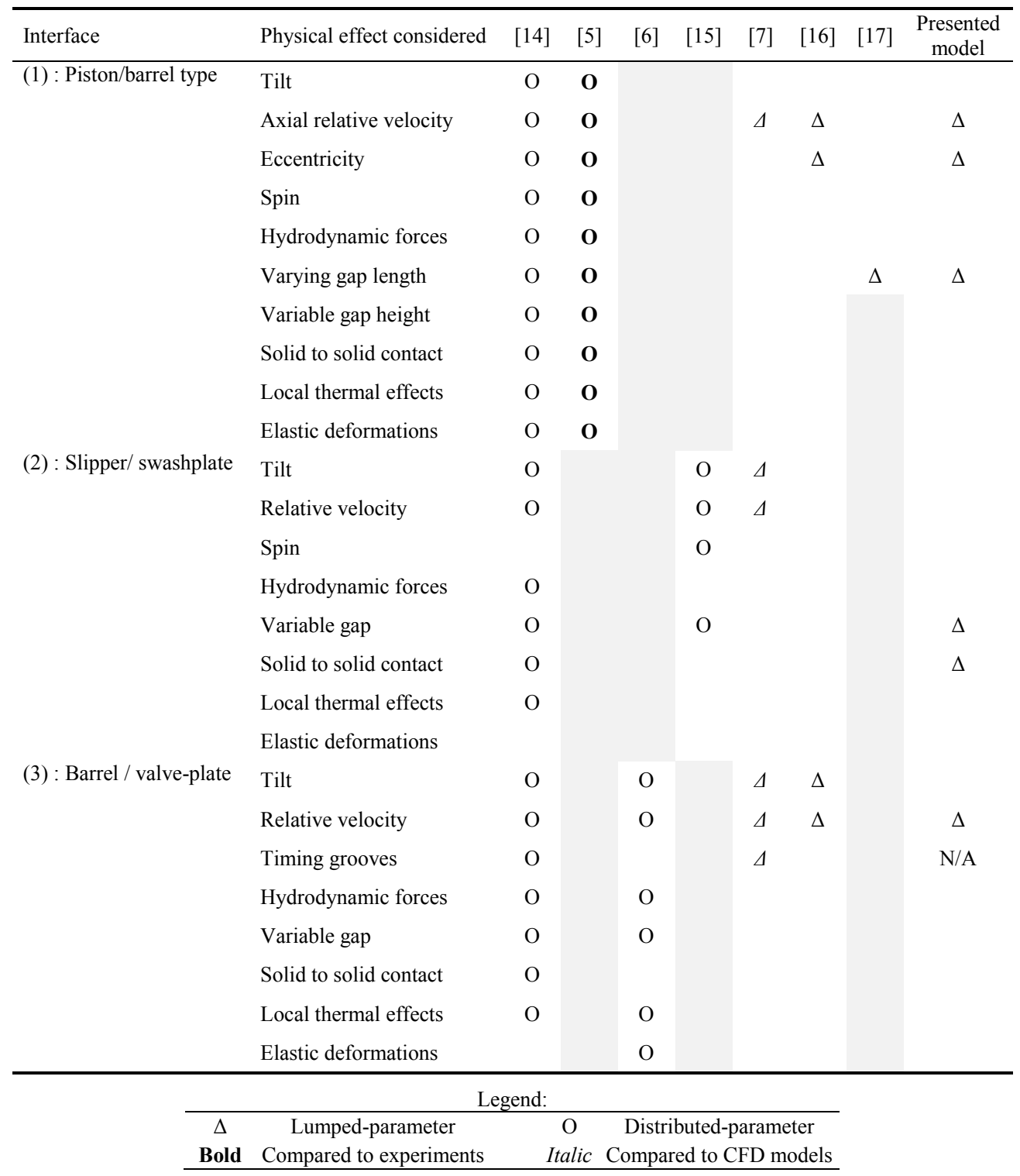

\subsection{Generic OD leakage pair models}

The Table 3 summarizes the well-known lumped-parameter models relative to the generic leakage sources that appear in pressure compensated, axial piston pumps [13]. Although several leakage paths exist at barrel/valve plate interface, only the leakage from a valve plate port to the case is considered in the table.
When used for the slipper/swashplate interface of the pump considered in the present work, this provides the numerical values of Table 4 if the pressure drop from piston chamber to slipper pocket is neglected. A constant gap height of 17 microns is used for the computation. This gap height is the one obtained from hydrostatic lift at 160 bar. To compute the total leakage $Q_{t}{ }^{*}$ for nine pistons, it is considered here that four piston 
chambers are at discharge pressure while the other five are at suction pressure.

For the pump used in this study, the supplier specified maximum allowed leakage is $1.5 \mathrm{~L} / \mathrm{min}$, but the result of the leakage computation for the slipper alone gives $97.5 \%$ of this maximum flow rate, without considering transient effects. This simple calculation shows that using the generic leakage model at slipper/swashplate interface leads to an unrealistic result.
In the current study, the authors aim at developing a lumped-parameter model with correct representation of the pump leakage. In order to improve the current state of the art for $0 \mathrm{D}$ models of the leakage interfaces, many physical effects can be taken into account. In the following part, a step forward to a more accurate model of the swashplate/slipper leakage through a variable gap height using a lumped-parameter approach is discussed.

Table 3: Generic pump leakage lumped-parameter models with pump cut adapted from [14]

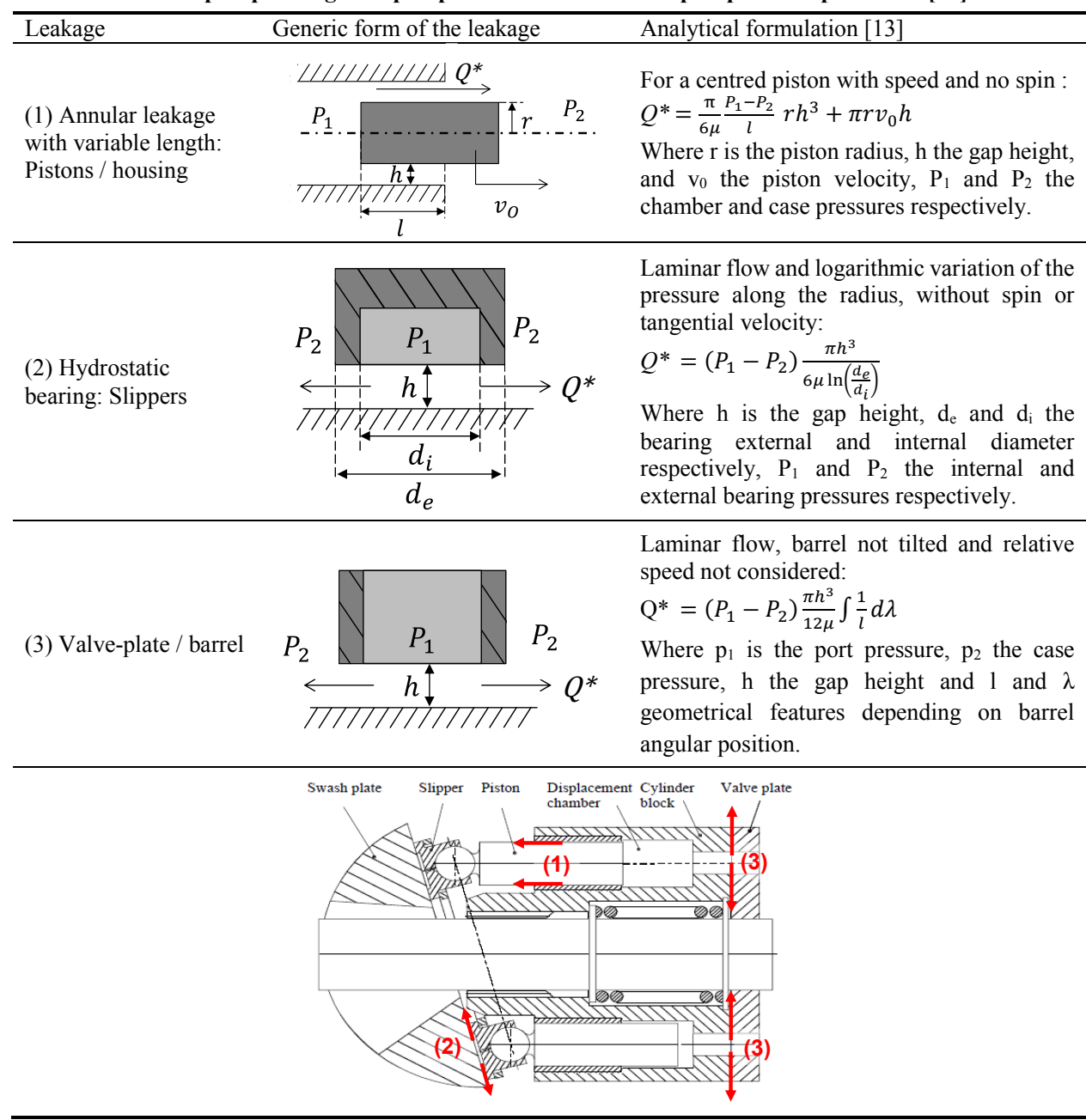

Table 4: Total leakage from slipper/swashplate interface using the generic leakage model

\begin{tabular}{lccccc}
\hline Variable & $P p[\mathrm{bar}]$ & $P c[\mathrm{bar}]$ & $h[\mu \mathrm{m}]$ & $Q^{*}[\mathrm{~L} / \mathrm{min}]$ & $Q_{t}{ }^{*}[\mathrm{~L} / \mathrm{min}]$ \\
\hline \multirow{2}{*}{ Value } & 160 & \multirow{2}{*}{3} & 17 & 0.37 & \multirow{2}{*}{1.463} \\
& 1.8 & & & -0.0034 & \\
\hline
\end{tabular}




\subsection{Proposition of a slipper/swashplate variable gap model}

It is today well known from experiments [19] and 3-D simulation, e.g. [14], that the effective geometries of the gaps are not as ideal as the ones that enable formal calculations. The facing surfaces are not parallel and affected by parasitic additional motion, e.g. tilting and spinning of the slipper. However, the lumped-parameter models of axial piston pumps in literature only considered constant gap heights, and/or parallel surfaces, e.g. [7, 9, 16, 17]. In the particular case of the slipper/swashplate, there is very little consideration to the action of the retainer and to the pumping effect in the case domain.

As a step forward, the variable gap is proposed for the slipper/swashplate interface, with the following assumptions:

- There is no tilt of the slipper, slipper axis remains perpendicular to the swashplate plane;

- Hydrodynamic forces are neglected;

- Only 1-D displacements are considered, null component of the slipper/swashplate relative speed in the swashplate plane;

- All forces out of piston or slipper axial direction are neglected (no lateral friction, windage, centrifugal effect...).

\section{Model}

The gap height can be seen as the consequence of slipper and swashplate relative movement, which is constrained by the retainer. The kinematics without retainer is shown on Figure 4, where $h$ is the gap height and $\vec{y}$ is the axis of the piston.

Considering that there is no play between slipper and piston at pivot point $\mathrm{A}$, the geometric parameters and variables are linked by:

$l^{\prime}=y_{0} \cos \alpha-R \sin \alpha$

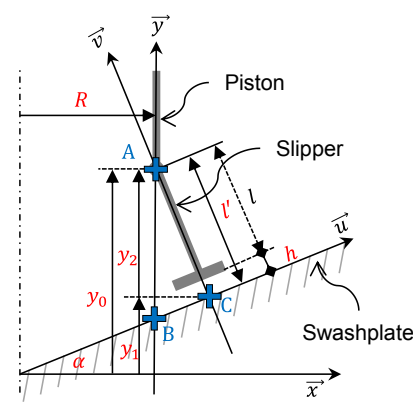

Figure 4: Schematics for the slipper/swashplate gap kinematics where $y_{0}$ is the piston axial position, and $\alpha$ the swashplate tilt angle. $R$ is the horizontal distance between the piston and the swashplate tilting axis defined as:

$R=-\frac{t_{d}}{2} \sin \theta$

with $t_{d}$ being the diameter of the piston trajectory along the barrel rotation, and $\theta$ the angular position of the piston axis with respect to the pump frame. Then the gap height temporal variation is:

$\dot{h}=\dot{l}^{\prime}=\dot{y}_{0} \cos \alpha-\dot{R} \sin \alpha-\dot{\alpha}\left[y_{0} \sin \alpha+\right.$

$R \cos \alpha]$

The position $y_{0}$ is linked to the force balance on the piston. Hydrostatic and friction forces due to chamber and case pressures, as well as the force applied by the slipper are considered. Friction losses and backlash at slipper/piston ball joint are neglected. The pressure forces and contact forces applied on the slipper on swashplate and retainer, applied on piston axial direction, give $F_{s l / p}$, the force applied on the piston by the slipper:

$F_{s l / p}=\left(F_{h b}+F_{\text {cont }}-F_{c / s l}\right) \cos \alpha$

The contact force $F_{\text {cont }}$ is modelled as an elastic end-stop model for both swashplate and retainer sides. Consequently, it can be either negative or positive depending on which solid is reached. $F_{c / s l}$ is the pressure force applied by the case fluid on the slipper back, and is written as:

$F_{c / s l}=\frac{\pi d_{e}^{2}}{4} P_{c}$

where $P_{c}\left(P_{2}\right.$ in Table 3$)$ is the case pressure. Considering laminar flow in the gap, the pressure force $F_{H B}$ on the slipper is:

$F_{H B}=P_{h b} S_{e q}=P_{p} \frac{\pi\left(d_{e}^{2}-d_{i}^{2}\right)}{8 \ln d_{e} / d_{i}}$

with $d_{e}$ and $d_{i}$ the external and internal diameters of the slipper bearing, respectively. The pressure $P_{h b}$ in the slipper pocket $\left(P_{1}\right.$ in Table 3$)$ is calculated from the mass conservation, from the flow from piston to slipper pocket (through the fixed short orifice), and from slipper pocket to pump case (through the slipper/swashplate gap), considering the fluid compressibility. The leakage flow in the gap is computed as expressed in Table 3.

The torque generated on the swashplate by the pressure force at slipper interface and by contact forces is also modelled. It is assumed that the 
slipper trajectory on the swashplate is circular, and that of the swashplate tilting axis passes through the centre of this trajectory.

\section{Model implementation}

The model is implemented in the Simcenter AMESim environment (v14) that is based on power bonds. However, due to the approach taken to express the gap height, a signal view is also taken to integrate the barrel rotating speed. The implemented model is given on Figure 5. The pressure force from the gap is considered through a piston $\boldsymbol{D}$ with the equivalent section $S_{e q}$. The gap height is bounded with an end-stop model 2 that also supplies the $F_{\text {contact }}$ force. The influence of the case pressure on the slipper is taken into account through the piston model 3. The projection of the forces on the slipper axis is made at $\mathbf{4}$. The leakage from the piston to the case flows through the first short orifice $\boldsymbol{\sigma}$, then through the slipper/swashplate gap $\boldsymbol{6}$ which is implemented as a variable orifice.

\section{Results}

In order to compare the simulation results from the model to that of the generic equations presented in part 3.1, a simulation of a single piston/slipper subassembly is made. Table 5 lists the numerical results for the mean simulated slipper leakage over one pump shaft revolution, computed with the same pressure boundary conditions as in Table 4. The total leakage at slippers $Q_{t}$ is compared to the generic model $Q_{t}{ }^{*}$ through relative error $(E r)$ computation $(E r=$ $\left.100\left(Q_{t}^{*}-Q_{t}\right) / Q_{t}^{*}\right)$. The total leakage at slippers $Q_{t}$ is at least $19.34 \%$ lower than that of the generic model $Q_{t} *$ (which is independent from swashplate yoke) whatever the pump displacement. It is interesting to note that at maximal pump displacement, the simulated leakage becomes negative, meaning that the slipper averagely sucks from the pump case.

Table 5: Comparison of total leakage at slipper/swashplate interface for 1 rev.

\begin{tabular}{lcccc}
\hline Variable & $\alpha[\mathrm{deg}]$ & $\begin{array}{c}Q_{t}{ }^{*} \\
{[\mathrm{~L} / \mathrm{min}]}\end{array}$ & $\begin{array}{c}Q_{t} \\
{[\mathrm{~L} / \mathrm{min}]}\end{array}$ & $\operatorname{Er}[\%]$ \\
\hline \multirow{3}{*}{ Values } & 0 & & 1.18 & 19.34 \\
& 5 & 1.463 & 0.9 & 38.48 \\
& 15.15 & & -0.29 & 119.82 \\
\hline
\end{tabular}

In order investigate this, the simulated slipper/swashplate clearance over two pump shaft revolutions is shown on Figure 6. The simulated gap height variation from this figure complies with measurements made in [19]. Figure 6 highlights two phenomena at low pump displacement. Firstly, the discharge (high) pressure generates slipper lift as predicted by hydrostatic bearings theory. The second phenomena is linked to case pressure. This last point is specific to the present application where forces from case pressure are implemented on slippers and pistons back sections. The parameterized slipper back section is larger than that of the piston, which leads to piston/slipper subassembly displacement towards the swashplate during the suction phase.

For high displacement, Figure 6 shows that the modelled pressure force under the slipper does not allow to lift it hydrostatically during the discharge phase. During the suction phase, the slipper is lifted up until it makes contact with retainer. As the case pressure is greater than the piston chamber pressure in this simulation, this movement leads to fluid intake at slipper. Both facts (no lift at discharge phase and fluid intake

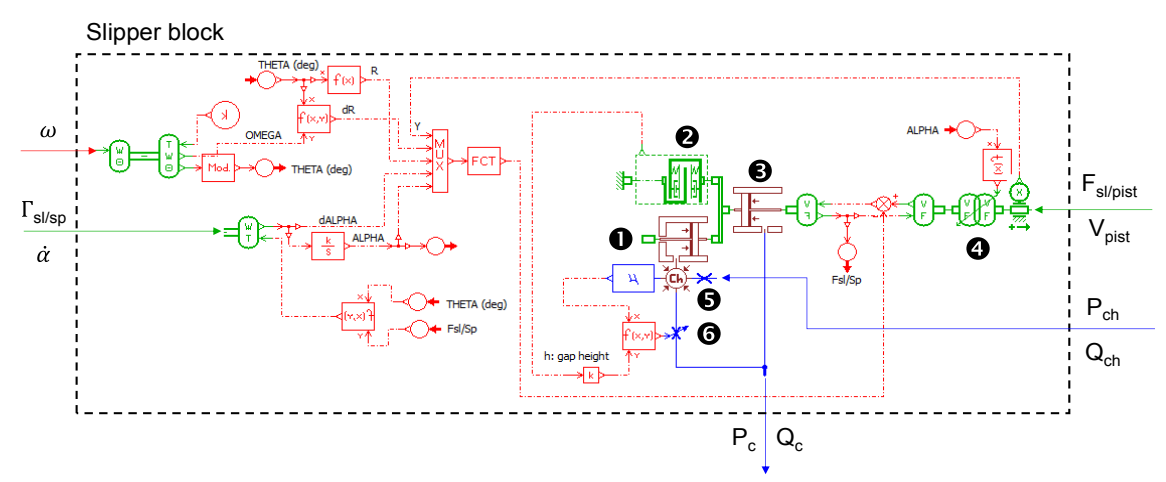

Figure 5: Implementation of the slipper model in Simcenter AMESim (v14) 


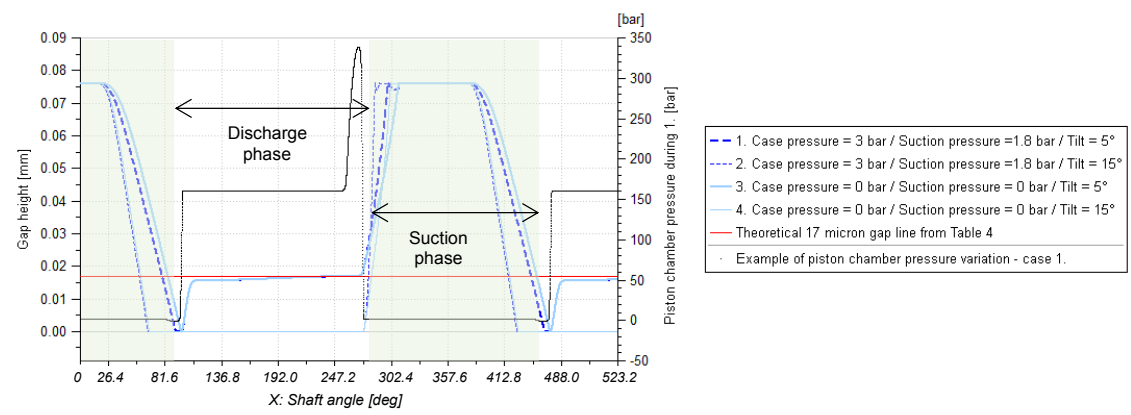

Figure 6: $\quad$ Slipper/swashplate gap height over pump rotation in several simulation cases

during suction phase) explain the overall negative slippers leakage. Considering this result and the presence of contacts between slipper and swashplate, hint at the need to develop, integrate and validate a more detailed model that includes additional degrees of freedom.

\section{CONCLUSION AND OUTLOOK}

The development of a lumped-parameter model of an axial piston pump under industrial constraints has been presented. The model aims at assessing the feasibility of leakage monitoring through the measurement of the pump case pressure, leading to the need of pump leakage paths accurate modelling.

The model architecting in the industrial context has been addressed in order to facilitate the building of a durable and capitalized model. This lead to select an architecture based on the pump topology.

The state of the art in axial piston pumps modelling has been summarized to point out the well-established or missing knowledge. Then, a slipper/swashplate lumped-parameter model with variable gap height has been proposed to improve the representativeness of the current 1-D models, which are lacking in accuracy compared to distributed-parameter models. It has been shown that the proposed model shows less slipper-due leakage over a pump revolution than the generic model. However, the variable gap model is highly dependent on the case and suction pressures as well as pump displacement. Simulation results show that the slipper and the swashplate enter into contact at high pump displacement, which is not realistic.

Several improvements to the variable gap model are foreseen. One of them consists in introducing the slipper tilt. To this end, forces in every direction must be taken into account, leading to a 3-D lumped-parameter model. Another option consists in generating metamodels from CFD simulation, to supply the gap height to the model as a function of operating conditions. This approach would also enable introducing hydrodynamic effects that are currently missing in the presented model. Both options will be studied and compared in terms of final computation time and physical representativeness.

\section{ACKNOWLEDGEMENTS}

The authors thank Mr G. Paulmann from Airbus Helicopters for his technical inputs, support and kind reviews during this research project.

\section{NOMENCLATURE}

$\begin{array}{ll}\alpha & \text { Swashplate tilt [rad or deg] } \\ \theta & \text { Piston axis angular position [rad] } \\ \mu & \text { Fluid dynamic viscosity [Pa.s] } \\ \omega_{b, m} & \text { Rotating speed (base or motor) [rad } / \mathrm{s}] \\ \Gamma_{b, m} & \text { Torque on pump (base or motor) [N.m] } \\ \Phi & \text { Thermal flux [W] } \\ d & \text { Slipper bearing diameter [m] } \\ t_{d} & \text { Piston circular trajectory diameter [m] } \\ d & \text { Slipper bearing diameter [m] } \\ F & \text { Force [N] } \\ h, \dot{h} & \text { Gap height and temporal variation [m, m/s] } \\ l^{\prime}, \dot{l} l^{\prime} & \text { Variables defining slipper kinematics [m, m/s] } \\ P & \text { Pressure [Pa or bar] } \\ Q & \text { Flow [m }{ }^{3} / \mathrm{s} \text { or L/min] } \\ Q^{*} & \text { Theoretical leakage flow at one slipper [L/min] } \\ R, \dot{R} & \text { Variables defining slipper kinematics }[\mathrm{m}, \mathrm{m} / \mathrm{s}] \\ S_{e q} & \text { Equivalent hydrostatic surface on slipper }\left[\mathrm{m}^{2}\right] \\ T & \left.\text { Pump temperature [ }{ }^{\circ} \mathrm{C}\right] \\ y, \dot{y} & \text { Piston displacement and velocity [m, } \mathrm{m} / \mathrm{s}]\end{array}$




$\begin{array}{ll}\text { Recurrent subscripts } \\ c & \text { Case } \\ \text { ch } & \text { Piston chamber } \\ \text { cont } & \text { Contact } \\ d & \text { Discharge } \\ e & \text { External } \\ h b & \text { Hydrostatic bearing } \\ i & \text { Internal } \\ p & \text { Piston } \\ s & \text { Suction } \\ s l & \text { Slipper } \\ t & \text { Total due to slippers (over 1 rev) }\end{array}$

\section{REFERENCES}

[1] Paulmann G, Mkadara G (2018) Condition Monitoring of hydraulic pumps - lessons learnt. 11th Int. Fluid Power Conf., March 19-21, Aachen, Germany

[2] Torikka T (2001) Evaluation of Analysis Methods for Fault Diagnosis on Axial Piston Pumps. Proc. of the Twelfth Scandinavian International Conf. on Fluid Power (SICFP), Tampere, Finland, 18-20 May

[3] Gao Y, Zhang Q (2006) A wavelet packet and residual analysis based method for hydraulic pump health diagnosis. Proc. of IMechE, vol. 220 Part D: J. Automobile Engineering, pp. 735745

[4] Kwan C, Xu R, Zhang X (2003) Fault Detection and Identification in Aircraft Hydraulic Pumps using MCA. Proc. of IFAC Symposium on Fault Detection, Supervision and Safety for Technical Processes, Washington, D.C., USA

[5] Pelosi M, Ivantysynova M (2009) A Novel Fluid-structure Interaction Model for Lubricating Gaps of Piston Machines. Proc. of the Fifth Fluid Structure Interaction Conf., eds. C.A. Brebbia, WIT Press, Southampton, pp. 1324

[6] Ivantysynova M, Baker J (2009) Power Loss in the Lubricating Gap between Cylinder Block and Valve Plate of Swash Plate Type Axial Piston Machines, International Journal of Fluid Power, 10:2, 29-43

[7] Bergada J M, Kumar S, Davies D Ll, Watton J (2012) A complete analysis of axial piston pump leakage and output flow ripples. Applied Mathematical Modelling, Vol. 36, Iss. 04, pp 1731-1751

[8] Poole K, Raeth M, Thielecke F, Mädige C (2011) Leakage Diagnosis for Electric Motor Pumps in Aircraft Hydraulic Systems. Deutscher
Luft - und Raumfahrtkongress, September 2729, Bremen, Germany

[9] Mancò S, Nervegna N, Lettini A, Gilardino L (2002) Advances in the simulation of axial piston pumps. Proc. of the Fifth JFPS International Symposium, Nara, Japan

[10] Deléchelle O (2019) From CAD to Simulation A Smooth Workflow to Model Axial Piston Pumps for EDP/EHA Systems, SIEMENS Digital Industry Software, Presentation at SAE A-6 meeting

[11] Maré J-C, Akitani S (2018) Foundation for Virtual Prototyping of Mechanical Power Management Functions in Actuators. Proceedings of the BATH/ASME 2018 Symp. on Fluid Power and Motion Control FPMC2018 September 12-14, Bath, UK

[12] Maré J-C (2019) Best practices for model-based and simulation-aided engineering of power transmission and motion control systems. Chinese Journal of Aeronautics, Elsevier, 32(1), p.186-199

[13] Ivantysyn J, Ivantysynova M (2003) Hydrostatic Pumps and Motors: Principles, Design, Performance, Modelling, Analysis, Control and Testing. Tech Book International

[14] Wieczorek U, Ivantysynova M (2002) Computer Aided Optimization of Bearing and Sealing Gaps in Hydrostatic Machines-The Simulation Tool Caspar. Int. Journal of Fluid Power, 3:1, 7-20

[15] Chao Q, Zhang J, Xu B, Wang Q (2018) Discussion on the Reynolds equation for the slipper bearing modeling in axial piston pumps, Tribology International, Vol. 118, pp 140-147

[16] Aaltonen J (2016) Interaction of Bootstrap Reservoir and Hydraulic Pump in Aircraft Hydraulic Systems. PhD Dissertation, Tampere University of Technology, Finland

[17] Simcenter AMESim demo TwoDOFSwash. Model of a pressure compensated axial piston pump of the swash plate design. Available via software help menu

[18] Schenk A T (2014) Predicting lubrication performance between the slipper and swashplate in axial piston hydraulic machines. Open Access Dissertations. 359. Available at http://docs.lib.purdue.edu/open_access_disserta tions $/ 359$

[19] Chao Q, Zhang J, Xu B, Wang Q (2018) Multiposition measurement of oil film thickness within the slipper bearing in axial piston pumps. Measurement, Vol. 122, pp 66-72 